drinkers 16 and 8 , alcoholics 39 and 21 (social drinkers $4 \cdot 1$ and $2.4 \mathrm{mmol} / \mathrm{l} / \mathrm{h}$, non-drinkers 3.5 and 1.7 , alcoholics 8.5 and 4.6). ${ }^{56}$ But probably these values do not apply to all groups in the community. Back calculation along these extremes of slope gives the range of blood alcohol concentration at the time of the accident that might have led to the measured value. This range can be narrowed by adjusting for the person's weight, build, age, sex, and body fat.

Even with several timed blood specimens, however, the standard slope still has to be used because present assays are not precise enough to calculate accurately the person's own slope. ${ }^{47}$ There are also serious constraints on the timings between which the back projections can be made. These arise because the blood alcohol concentration is not predictable when absorption is still occurring ${ }^{8}$ and because the slope departs appreciably from linearity at low alcohol concentrations. When some $30 \mathrm{~g}$ of alcohol is drunk over a short period ( 5 minutes) on an empty stomach the blood concentration rises quickly to produce a peak between 30 and 60 minutes; then the concentration declines in a near linear fashion for about four hours. When the concentration approaches 20 $\mathrm{mg} / 100 \mathrm{ml}(4.3 \mathrm{mmol} / \mathrm{l})$ the curve becomes non-linear and back extrapolation is invalid. If the same quantity of alcohol is taken slowly and with food the blood concentration rises less sharply to a more rounded peak and gradually turns into a linear downward slope after about three hours as the rate of absorption falls below the removal rate. During this absorption phase the blood alcohol concentration may be much lower than when the alcohol is drunk rapidly, and it is not valid to extrapolate back into this absorption phase from the subsequent linear slope. When alcohol has been drunk after an accident ("the hip flask defence") attempts to allow for this require either an estimate or "calibration" of the person with alcohol, 9 but this calibration may be invalid if measurements are delayed for many weeks or months.

Where it can be verified that a motorist of normal physique has not had alcohol in the previous two to three hours then determination of the blood alcohol concentration by back calculation in the following two to three hours would provide a range of concentrations-albeit with wide confidence intervals - that are likely to be right. Additional evidencefor instance, that the person did not take food with the drink, on the amount drunk, and on when it was drunkwill extend the valid "window" to an earlier time. But even with extra evidence it is difficult to be confident of blood alcohol concentrations in the hour after drinking - and this is the time when most accidents are likely to have happened.

K O LEWIS

Principal Biochemist,

Department of Clinical Chemistry,

Dudley Road Hospital,

Birmingham B18 7QH

1 Widmark EMP. Verteilung und Umwandlung des Athylalkohols im Organismus des Hundes Biochemische Zeitschrift 1933;267:128-34.

2 Newman HW, Lehman AJ, Cutting WC. Effect of dosage on rate of disappearance of alcohol from the blood stream. I Pharmacol 1937;61:58-61.

3 Wagner JG. Properties of the Michaelis-Menten equation and its integrated forms which are useful in pharmacokinetics. F Pharmacokinet Biopharm 1973;1:103-21

4 Wagner JG, Wilkinson PK, Sedman AJ, Kay DR, Weidler DJ. Elimination of alcohol from human blood. I Pharm Sci 1976;65:152-4.

5 Winek CL, Murphy KL. The rate and kinetic order of ethanol elimination. Forensic Sci In 1984;25:159-66.

6 Lewis MJ. Blood alcohol: the concentration time curve and retrospective estimation of level. I Forensic Sci Soc 1986;26:95-113.

7 Forrest ARW. Non-linear kinetics of ethyl alcohol metabolism. F Forensic Sci Soc 1986;26:121-3. 8 Madsen BW, Rossi L. Sleep and Michaelis-Menton elimination of ethanol. Clin Pharmacol Ther 1980;27:114-9.

9 Lewis MJ. The individual and the estimation of his blood alcohol concentration from intake, with particular reference to the "hip-flask" drink. I Forensic Soc 1986;26:19-27.

\section{Radiological diagnosis of deep vein thrombosis}

The clinical evaluation of deep vein thrombosis is very inaccurate. Some two thirds of thromboses in the legs cause no symptoms and half the diagnoses made on clinical grounds alone will be wrong. ${ }^{1}$ Hence it is important to evaluate the other methods of diagnosis.

Venography of the legs remains the gold standard against which all other methods have to be judged. The introduction of low osmolar contrast media has greatly reduced the upsets caused by venography, ${ }^{23}$ but a search has also been made for methods which are less invasive and avoid the use of $x$ rays. Both impedance plethysmography and Doppler ultrasonography are highly sensitive in diagnosing occlusive deep vein thrombosis in the iliac and femoral veins but are much less so in detecting thrombosis in the lower leg as well as the potentially dangerous proximal non-occlusive thrombosis. ${ }^{45}$ "Duplex" ultrasonic scanning - that is, the combination of pulsed Doppler and real time B mode imaging-requires expensive equipment and has not been evaluated in patients with suspected deep vein thrombosis. Radionuclide imaging using fibrinogen labelled with iodine-125 requires at least 2448 hours before a diagnosis can be made and cannot be used in pregnant or lactating women; it is sensitive in detecting thrombi in the calf but less so in the proximal veins. ${ }^{6}$ Technetium- $99 \mathrm{~m}$ has been tagged to fibrinogen and other blood products, ${ }^{7}$ but imaging using these combinations has not been as accurate as venography.

Recently real time B mode ultrasound scanning, usually with a $7.5 \mathrm{MHz}$ transducer, has been evaluated for confirming or excluding deep vein thrombosis. It is quick, it uses standard equipment that is available in most $x$ ray departments, and many radiologists are skilled in ultrasonic scanning. The results from different centres have been remarkably consistent: a specificity of $89-94 \%$ and a sensitivity of $100 \%$. $^{8-11}$ The visualisation of thrombus is the most specific diagnostic criterion. ${ }^{8}$ Acute and chronic thrombi can often be distinguished by ultrasound: typically the latter are highly echogenic, ${ }^{12}$ and the former are not. ${ }^{13}$ Finding clot floating free in the lumen of the vein is further evidence of recent thrombosis ${ }^{8}$ and compressibility of the vein by the ultrasound pulse is another sensitive and reproducible indicator. ${ }^{11} 13$ The common femoral vein may fail to distend in response to the Valsalva manoeuvre in ileofemoral venous occlusion. ${ }^{14}$ Venous compression should distinguish the slow moving echoes which arise in the lumen from venous stasis caused by thrombosis higher in the vein, cardiac failure, or ischaemia of the leg..$^{15}$

Real time scanning of the venous system cannot show up the calf veins (except occasionally for their proximal portions) and the iliac veins. ${ }^{11}$ Another blind area on ultrasonography is the popliteal-femoral segment in the region of the adductor opening. ${ }^{10}$ Nevertheless, most workers consider that thrombi limited to the calf veins are unlikely to give rise to embolism, ${ }^{16}$ and they often resolve within 72 hours without anticoagulant treatment. ${ }^{17}$

So what conclusions can we reach about the roles of ultrasonography and venography in practice? Given a radiologist skilled in ultrasonography, this method is an accurate way of excluding or confirming thrombus in the femoropopliteal segment. When a radiologist does not have this skill venography of the leg remains a first line investigation for suspected thrombosis there and in the iliac veins. An 
additional advantage of ultrasound is that it may show conditions that mimic deep vein thrombosis, such as haematoma, abscess, ${ }^{18}$ and ruptured Baker's cyst. ${ }^{10}$

\section{GRAHAM WHITEHOUSE}

Professor of Diagnostic Radiology,

University of Liverpool,

Liverpool L69 3BX

1 Salzman EW. Venous thrombosis made easy. N Engl f Med 1986;314:847-8.

2 Albrechtsson $U$, Olsson CG. Thrombosis following leg phlebography with ionic and non-ionic contrast media. Acta Radiol (Diagn) 1979;20:46-52.

3 Thomas ML, Briggs GM. Low osmolality contrast media for phlebography. Intemational Angiology 1984;3:73-6.

4 Jeffrey PC, Immelman EJ, Benatar SR. Comparison of impedance plethysmography with ascending venography for the diagnosis of proximal deep vein thrombosis. $S$ Afr Med $\mathcal{J}$ 1985;67:15-8.

5 Ramchandani P, Soulen RL, Fedullo LM, Gaines VD. Deep vein thrombosis: Significan limitations of non invasive tests. Radiology 1985;156:47-9.

6 Harris WH, Salzman EW, Athanasoulis C, et al. Comparison of ${ }^{125}$ I-fibrinogen count scanning with phlebography for detection of venous thrombi after elective hip surgery. $N$ Engl f Med 1975;292:665-7.

7 Sandler DA, Martin JF, Duncan JS, et al. Diagnosis of deep vein thrombosis: comparison of clinical evaluation, ultrasound plethysmography, and venoscan with $x$-ray venogram. Lancet 1984;ii:716-9.

8 Sullivan ED, Peter DJ, Cranley JJ. Real-time B-mode venous ultrasound. $f$ Vasc Surg 1984;1: 465-71.

9 Dauzat MM, Laroche JP, Charras C, et al. Real-time B-mode ultrasonography for better specificity in the non-invasive diagnosis of deep vein thrombosis. $\mathcal{O}$ Ultrasound Med 1986;5 625-31.

10 Aitken AGF, Godden DJ. Real-time ultrasound diagnosis of deep vein thrombosis: a comparison with venography. Clin Radiol 1987;38:309-13.

11 Cronan JJ, Dorfman GS, Scola FH, Schepps B, Alexander J. Deep venous thrombosis: US assessment using vein compression. Radiology 1987;162:191-4.

12 Coelho JC, Sigel B, Ryva JC, Machi J, Renigers SA. B-mode sonography of blood clots. $f$ Clin Ultrasound 1982;10:323-7.

13 Raghavendra BN, Horii SC, Hilton S, Subramanyam BR, Rosen RJ, Lam S. Deep venous thrombosis: detection by probe compression of veins. J Ulurasound Med 1986;5:89-95.

14 Effeney DJ, Friedman MB, Gooding GAW. Ileofemoral venous thrombosis: real-time ultrasound diagnosis, normal criteria, and clinical application. Radiology 1984;150:787-92.

diagnosis, normal criteria, and clinical application. Radiology 1984;150:787-92.
15 Machi J, Sigel B, Beitler JC, Coelho JC, Justin JR. Relation of in vivo blood flow to ultraound echogenicity. I Clin Ultrasound 1983;11:3.

16 Moser KM, Le Moire JR. Is embolic risk conditioned by location of deep venous thrombosis. Ann Intern Med 1981;94:439-44.

17 Kakkar VV. Deep vein thrombosis: detection and prevention. Circulation 1975;51:8-19.

18 Bell JM, Ross FGM, Mackenzie S, Goddard PR. The swollen leg: ultrasonographic demonstration of non thrombotic cases. Postgrad Med $\mathcal{J}$ 1985;61:23-7.

\section{Walking through labour}

The horizontal position, either supine or lateral, is often claimed to have been devised by the modern obstetrician to allow him easier access to the perineum, but traditional birth attendants in primitive tribes have for centuries nursed women horizontally. In Europe Francois Mauriceau advocated a supine position for delivery but an upright posture in labour as early as the seventeenth century, ${ }^{1}$ and similar advice was proffered by William Smellie ${ }^{2}$ some 50 years later. Since then many reports on posture in labour have been published-and they have been well reviewed recently by Lupe and Gross. ${ }^{3}$

Most obstetricians allow a woman to adopt any position she wants during labour. They might constrain walking when continuous fetal heart rate monitoring is needed or when the woman has ruptured her membranes in early labour. As we become more familiar with the benefits and limitations of fetal heart monitoring many obstetricians are selecting fewer women for continuous recording throughout labour. The obstetrician could allow walking during labour even in a woman he wished to monitor by using the cheap radiotelemetry that allows freedom from attachments to the cardiotocograph machine. The concern about walking after the membranes have ruptured arises because of the risk of the umbilical cord prolapsing ahead of the presenting part. Usually, however, the head presents, and if it is engaged the risk of a prolapsed cord is greatly reduced.

The supine position should be avoided at any stage of labour. The hazards of supine hypotension, particularly among those women receiving epidural anaesthesia, are well documented. ${ }^{4}$ Further, both Turnbull' and Caldeyro-Barcia et $a l^{6}$ have claimed that the lateral position is better for uterine action than the supine position. Several groups have claimed that standing and walking not only shorten labour but also ease the discomfort of the mother..$^{7.9}$ Labour in the vertical position, on the other hand, is associated with increases in contraction intensity but not with contraction frequency, ${ }^{810}$ increases in total uterine activity, and higher resting intrauterine pressures. ${ }^{11}$ Read $e t a l^{11}$ have suggested that the upright posture may be as effective as oxytocin for augmenting an inefficient labour.

Others argue that walking is a consequence not the cause of an easy labour. ${ }^{12-15}$ What is clear is that many of these studies are deficient in design and size. Although women in all but one study were ostensibly randomised into alternate postures, randomisation was often poor. Further, the sample size in the biggest study was $\mathbf{3 7 0}$ women and in four of the surveys was less than 100 . Uncontrolled periods of walking and inexact definitions of labour further complicated the picture.

Walking thus does not increase the risk to mother or fetus, but does it lead to any benefits? We need a rigorously performed randomised controlled trial of walking against bed rest in the first stage of labour to determine any precise benefit from either position. Until this is done women should be able to follow their instincts.

Geoffrey Chamberlain Professor

Malcolm Stewart Lecturer

Department of Obstetrics and Gynaecology, St George's Hospital Medical School,

London SW 17 ORE

1 Mauriceau F. Diseases of women with child and in childbed. Chamberlain $H$, transl. New York: Garland, 1985. (Des maladie des femmes grosses, et acouchées avec la bonne et véritable methode de les bien aider en leurs accouchemens naturels. Paris, 1668.)

2 Smellie $W$. Treatise on the theory and practice of midwifary. Vol 2. Circa 1718. (Edited by A H McClintock for the New Sydenham Society, London, 1876.)

3 Lupe PJ, Gross TL. Maternal upright posture and mobility in labour-a review. Obstet Gynecol 1986;67:727-34.

4 Crawford JS. Lumbar epidural analgesia for labour and delivery: a personal view. In: Studd J, ed. The management of labour. Oxford: Blackwell Scientific Publications, 1985:227.

5 Turnbull AC. Uterine contractions in normal and abnormal labour. Fournal of Obstetrics and Gynaecology of the British Empire 1957;64:321-3.

6 Caldeyro-Barcia R, Noriega-Guerra L, Cibils LA, et al. The effect of position changes in the intensity and frequency of uterine contractions in labor. Am $f$ Obstet Gynecol 1960;80:284-90. Mitre IN. The influence of maternal position on duration and active phase of labour. In $f$ Gymaecol Obstet 1974;12:181-3.

8 Mendez-Bauer C, Arroyd J, Garcia-Ramos C, et al. Effects of standing position on spontaneous uterine contractility and other aspects of labor. $₹$ Perinat Med 1975;3:89-100.

Dunn PM. Posture in labour. Lancet 1978;i:496.

10 Flynn AM, Kelly J, Hollins G, Lynch PF. Ambulation in labour. Br Med f 1978;ii:591-3.

10 Flynn AM, Kelly J, Hollins G, Lynch PF. Ambulation in labour. Br Med f 1978;ii:591-3. Read JA, Miller FC, Paul RH. Randomised trial of ambulation versus

12 McManus TJ, Calder AA. Upright posture and the efficiency of labour. Lancet 1978;i:72.

13 Williams RM, Thom MH, Studd JWW. A study of the benefits and acceptability of ambulation in spontaneous labour. Br $\mathcal{O}$ Obstet Gymaecol 1980;87:122-6.

14 Calvert JP, Newcombe RG, Hibbard BM. An assessment of radiotelemetry in the monitoring of labour. Br $\mathcal{O}$ Obsitet Gynaecol 1982;89:285-91.

15 Stewart P, Calder AA. Posture in labour: patients' choice and its effect upon performance. Br $\mathcal{J}$ Obstet Gynaecol 1984;91:1091-5. 